\title{
Carmen Licari, Des fleurs, des fruits et des légumes
}

\section{Carminella Biondi}

\section{(2) OpenEdition}

\section{Journals}

\section{Edizione digitale}

URL: http://journals.openedition.org/studifrancesi/8402

DOI: 10.4000/studifrancesi.8402

ISSN: 2421-5856

\section{Editore}

Rosenberg \& Sellier

\section{Edizione cartacea}

Data di pubblicazione: 1 mai 2009

Paginazione: 218-219

ISSN: 0039-2944

\section{Notizia bibliografica digitale}

Carminella Biondi, «Carmen Licari, Des fleurs, des fruits et des légumes», Studi Francesi [Online], 157 (LIII | I) | 2009, online dal 30 novembre 2015, consultato il 09 janvier 2021. URL: http:// journals.openedition.org/studifrancesi/8402 ; DOI: https://doi.org/10.4000/studifrancesi.8402

Questo documento è stato generato automaticamente il 9 janvier 2021.

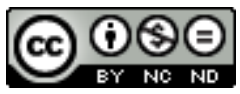

Studi Francesi è distribuita con Licenza Creative Commons Attribuzione - Non commerciale - Non opere derivate 4.0 Internazionale. 


\title{
Carmen Licari, Des fleurs, des fruits et des légumes
}

\author{
Carminella Biondi
}

\section{NOTIZIA}

CARMEN LICARI, Des fleurs, des fruits et des légumes, Paris, Société des écrivains, 2007,

pp. 118.

1 Dopo aver rievocato gli anni della sua formazione tunisina nel romanzo L'École bleue (2005), Carmen Licari affronta nel suo ultimo libro - una raccolta di 25 brevi e talvolta brevissimi racconti - il tema del vivere quotidiano con i suoi semplici piaceri da assaporare, le sue banali difficoltà da superare, le risposte giuste da dare al momento giusto, le cose da dire e da non dire, le decisioni da prendere... Un piccolo mondo da cui Carmen Licari sa ricavare una poesia in tono minore ma fortemente evocativa, che dà ai minuti eventi, alle piccole cose solitamente marginali e non degne di interesse, il carisma della centralità. Basti pensare al primo racconto dedicato ai frutti e ai legumi o a quello intitolato Omelette aux courgettes, o a Dialogues. Eventi, gesti, oggetti marginali cessano di essere tali non perché muti il loro valore intrinseco nella scrittura, ma perché diventano un reagente in cui si rivelano una visione della vita e del mondo ed una personalità. Uno sguardo acuto, spietato e benevolo ad un tempo, quello di Carmen Licari, che le permette di cogliere i riti, talvolta maniacali, di ogni esistenza e di fissarli sulla pagina in immagini e ritratti indimenticabili. Così, l'ovvio e il quotidiano diventano, sotto la sua penna, delle piccole epopee esistenziali. La narrazione è servita da una scrittura bellissima, che è il risultato congiunto di una raffinata sensibilità linguistica e di una grande conoscenza delle sottigliezze della lingua. Questa congiunzione felice di sensibilità e di sapienza fa sì che anche le parole e le espressioni più semplici riescano a trasmettere alla materia trattata sonorità e significati inattesi.

2 Sono racconti che fanno pensare a Nathalie Sarraute e alla sua sotto-conversazione, ma mentre in Sarraute si colgono talvolta il travaglio della scrittura e lo stridore dei 
meccanismi che si mettono in movimento per ottenere l'effetto di reale, qui tutto sembra scorrere con estrema semplicità e con, almeno apparente, serenità. Anche se non mancano qua e là piccoli squarci sugli abissi del vivere: un Tu ne te souviens pas? che fa intuire il dramma della perdita della memoria, mentre un titolo apparentemente anodino come Notre pain de chaque jour evoca, attraverso Camus e il ritorno alla Tunisia natale, l'indicibile, rappresentato dalla morte della madre. E non è meno inquietante, anche se certamente meno drammatica, l'incertezza di fronte alle scelte o alle piccole decisioni, un'incertezza che rasenta talvolta l'impotenza e l'inazione. La raccolta offre uno straordinario, seppur minimale, spaccato di vita in cui molti di noi non faticheranno a riconoscersi. 